\title{
Review of The Mayor of Moultrie Avenue
}

\author{
Christine Miller, Georgia State University
}

When Carl Walworth began volunteering as a literacy tutor in Mattoon, Illinois, he did not realize that he was making a 24-year commitment and a lifelong friend in Eldo, his student. The Mayor of Moultrie Avenue: The Literacy Journey of an Unlikely Pair serves as both a memoir and a description of an adult literacy tutoring relationship. While working at the local newspaper as a reporter, Carl began volunteering with a local literacy program as a tutor. Part of what motivated him was curiosity about adults who struggle with reading.

Throughout his narrative, Carl actively contrasts and compares himself to Eldo as a means for better understanding the complexities of adult literacy in the United States. Eldo is a generation older than Carl, but they both come from small towns in Illinois. While they have led parallel lives in some ways, socioeconomic class divides them in other ways. The child of educators, Carl initially cannot understand how an individual can go to school and not achieve literacy proficiency. Further, Carl's parents raised him with the middle class assumption that college followed high school graduation. Carl's relationship with Eldo helps him to see how socioeconomic class narrows or widens opportunities and expectations.

As a child of the 1950s in a working class neighborhood of Mattoon, Illinois, Eldo struggled with reading even though his reading delays were not remarkable to his family and friends. He began working to help his large family around the age of 12 , and it was felt that it was possible for him to grow up and make a comfortable living without advanced reading skills or a high school diploma. As Eldo became an adult, the changing economy of an 
increasingly automated and globalized United States constrained his ability to support his family, and it became progressively more difficult for him to do so. These changes meant that Eldo had to work harder for less money and fewer benefits. When he and Carl meet, Eldo has survived a major stroke, which left him permanently disabled along with other chronic health issues such as diabetes and an enlarged heart. By the end of the memoir, a fiftyish Carl himself experiences the effects of the changing economy in his own career at the newspaper, which is cut short by the Great Recession.

Carl Walworth gives an authentic account of the challenges facing adult tutors and their reading students. Adult learners must juggle jobs, family commitments, illnesses, etc., while working on increasing their reading skills. Carl layers the story of his tutoring relationship with Eldo by giving readers the historical background of Mattoon, sharing Eldo's own insights about how he survived with limited reading skills on the job, explaining how the literacy tutoring program operated, and offering practical tips for readers who may be interested in tutoring adults.

A strength of this book is that Carl personalizes the millions of adults who struggle with reading in the United States. Eldo is multi-dimensional; he is intelligent, resilient, and actively involved in his community despite struggling with limited reading skills. Tutoring milestones are described and one special one is their shared reading pleasure over Mark Twain's classic, The Adventures of Huckleberry Finn.

The book is not structured in a strictly linear fashion, which enlivens the story. The writing is strongest when Carl dons his reporter's cap and gives his writing a clearer, more objective tone. While Carl gives general information about assessing progress and reading activities with his students, more details about this aspect of tutoring would have been interesting to readers who are involved in adult basic education. In addition, Carl provides many details that are not related to literacy, such as information about the community and his own life. The details are not tightly connected to the tutorial relationship and therefore at times the descriptions are a bit tedious.

This book is best suited for individuals who are unfamiliar with adults who have difficulty reading and who want to learn more about the experience a tutor can have with a learner. The book concludes with ideas about places where volunteers can help others with reading including community programs, schools, libraries, community colleges, and faith based organizations. There is a section at the end of the book which provides a list of adult literacy resources. I recommend this book for those who are not familiar with adult literacy learners and tutors. Through his tutorial relationship with Eldo, Carl Walworth connects the dots between literacy, education, healthcare and poverty in blue collar, Middle America. 